\title{
Evaluasi lanskap taman kota alun-alun Kapuas
}

\author{
Kartini ${ }^{1 \star}$, Agus Ruliyansyah ${ }^{1}$, Nur Arifin ${ }^{1}$ \\ 1. Program Studi Agroteknologi, Fakultas Pertanian Universitas Tanjungpura, Indonesia 78124 \\ *E-mail:kartini_ikhwafillah@yahoo.com
}

\begin{abstract}
Landcape evaluation of alun-alun Kapuas City park. Kapuas city park is a Green Open Space (RTH) that has aesthetic, ecological, social and economic functions. The condition of the park recently has the potential to differ from the previous design. The purpose of this research is to evaluate the condition of Alun-Alun Kapuas city park including theme, plants' condition, and community perception. The method used in this research is: survey, interview and questionnaire. Data analysis using quantitative approach that descriptively interpreted. The results showed that the concept of repetition and suppressor in good condition, but it is imbalance. For the plants' condition, it is divided into three condition: good condition $81,13 \%$, average condition 9,43\%, and bad condition $9.43 \%$. Community perception about Kapuas City Park is $54 \%$ rate for average condition, $56 \%$ rate good for the park quality. Kapuas City Park is recently in a good, average, and bad condition. The good and average conditions can be maintained by giving information, making bulletin boards, hedges and signage. The bad condition can be improved by replanting to keep the theme on the park so the Kapuas City Park can be functioned properly.
\end{abstract}

Keywords: evaluation, landscape city park, square park.

\section{Pendahuluan}

Taman Alun-Alun Kapuas merupakan salah satu "Open Publik Space" yang disediakan oleh Pemerintah Kota Pontianak Provinsi Kalimantan Berat. Taman Alun-Alun Kapuas terletak di pinggiran Sungai Kapuas. Taman Alun- Alun Kapuas merupakan tempat yang indah dan nyaman untuk bersantai sambil menikmati pemandangan Sungai Kapuas dan juga terdapat berbagai tanaman sebagai peneduh dan penghias taman sehingga menambah kenyamanan pengunjung.

Taman Alun-Alun Kapuas merupakan taman kota bagian dari Ruang Terbuka Hijau (RTH) yang memiliki fungsi estetika, ekologis, sosial dan ekonomi. Fungsi estetika tanaman digunakan untuk memberikan keindahan dan kenyamanan. Estetika tanaman dapat memberikan seni hidup untuk meningkatkan kualitas visual lingkungan dengan penampilan warna, dan bentuk arsitektur taman. Sedangkan fungsi ekologis RTH yaitu dapat meningkatkan kualitas air tanah, mencegah banjir, mengurangi polusi udara dan pengatur iklim mikro. Fungsi lainnya yaitu sosial-ekonomi untuk memberikan fungsi sebagai ruang interaksi sosial, sarana rekreasi dan sebagai tetener (landmark) kota.

Penataan lanskap yang baik diperlukan untuk mewujudkan suatu taman RTH. Penataan dapat dilakukan terhadap elemen lanskap sebagai unit pembentuk lanskap, yaitu berupa keseimbangan, pengulangan dan penekanan. Elemen-elemen tersebut secara langsung maupun tidak langsung dapat mempengaruhi penampilan dan kualitas taman itu sendiri. Menurut Arifin et al. (2008), dalam perancangan taman perlu dilakukan pemilihan dan penataan secara detail terhadap elemen-elemen tanaman agar suatu taman dapat memiliki nilai fungsional dan estetika.

Kondisi Taman Alun-Alun Kapuas saat ini berpotensi mengalami pergeseran dari rancangan sebelumnya, maka perlu dilakukan evaluasi terhadap kondisi Taman Alun-Alun Kapuas yang sekarang bahwa Taman Alun-Alun Kapuas belum ada peneliti yang mengupas masalah evaluasi lanskap dan sebagainya. Penelitian ini dilakukan untuk mengevaluasi kesesuaian tema, kondisi tanaman lanskap dan persepsi masyarakat terhadap kondisi Taman Alun-Alun Kapuas sebagai taman RTH. 


\section{Metode}

Penelitian dilaksanakan di Taman Alun-Alun Kapuas yang terletak di Kota Pontianak Jalan Rahadi Usman. Peneltian ini dilakukan selama enam bulan dari tanggal 27 Maret sampai 27 September 2017. Metode yang digunakan dengan teknik survey, wawancara dan kuisioner. Pelaksanaan evaluasi dilakukan dengan tahapan: (1) observasi, (2) wawancara, (3) kuesioner, (4) studi pustaka, dan (5) dokumentasi. Analisis data menggunakan pendekatan kuantitatif yaitu berkaitan dengan data-data numerik kemudian hasilnya di interprestasi secara deskriptif. Analisis data berupa : (1) kesesuaian tema desain dilakukan dengan membandingkan tema pada awal perencanaan dengan kondisi yang sekarang, (2) kondisi tanaman dilakukan dengan melihat kriteria pertumbuhan tanaman, fungsi tanaman, skesesuaian hidup tanaman, dan keindahan tanaman, (3) persepsi masyarakat dikumpulkan melalui kuisioner yang disebarkan secara langsung dan responden didampingi untuk mengisi kuisioner. Siteplan Taman Alun-Alun Kapuas dapat dilihat pada Gambar 1 di bawah ini.



Gambar 1. Profil Taman Alun-Alun Kapuas

\section{Hasil dan Pembahasan}

a. Kesesuaian Tema Taman Alun-Alun Kapuas

Kesesuaian tema Taman Alun-Alun Kapuas sebagai Ruang Terbuka Hijau (RTH) saat ini dimanfaatkan oleh masyarakat dengan baik. Ruang terbuka yang tersedia pada suatu kawasan perkotaan merupakan salah satu sarana bagi masyarakat untuk meningkatkan interaksi sosial baik diantara warga kota, maupun kepada lingkungan sekitarnya (Grey \& Deneke 1986). Keberadaan RTH dapat dimanfaatkan sebagai sarana pendidikan, tempat berkumpul, sarana rekreasi, dan tempat ibadah pada waktu-waktu tertentu. Pada bentukbentuk yang lain, RTH dapat bermanfaat sebagai pelengkap keindahan, sarana pengaman, pengarah pengguna jalan dan sebagai identitas suatu kota. Tersedianya kawasan hijau, merupakan salah satu aspek yang penting dalam rangka pembangunan nilai-nilai sosial suatu kota (Nagtegaal \& Nas 2000).

Taman Alun-Alun Kapuas merupakan RTH sesuai kondisi wilayah studi merupakan ruang yang terbangun, dimana pada setiap tahunnya Taman Alun-Alun Kapuas mengalami perubahan dengan adanya renovasi. Perubahan tersebut dapat dilihat dengan perbandingan unsur tanaman yang lebih luas, tanaman yang bermacam-macam jenis dan memiliki fungsi utama untuk perlindungan kawasan sekitarnya. RTH Taman Alun-Alun Kapuas juga sebagai pendidikan dan sosialisasi dimana terdapat rumah baca dan podium sebagai tempat interaksi. RTH juga memberikan hasil terhadap kebutuhan kenyamanan, kesejahteraan, peningkatan kualitas lingkungan, peningkatan wawasan, dan pelestarian alam.

Salah satu fungsi RTH secara sosial sebagai tempat rekreasi dimana masyarakat dapat melaksanakan kegiatan berbentuk rekreasi, kegiatan yang berupa aktif maupun pasif. Taman Alun-Alun Kapuas juga sebagai tempat pendidikan digunakan dengan baik, dimana terdapat rumah baca dalam kondisi yang baik, sehingga masyarakat dapat memanfaatkan rumah baca tersebut untuk menambah wawasan baru dan pengaaman. 
Konsep keseimbangan, pengulangan, dan penekanan dalam prinsip desain ditemukan pada Taman Alun-Alun Kapuas. Konsep ini untuk mencapai kesatuan dan keteraturan pada taman. Perinsip pengulangan ditemukan pada segmen taman dua, pengulangan pada spot-spot air mancur, dan pada taman segmen 3 bagian taman $A$ dan taman $B$ juga ditemukan spot-spot yang mengalami pengulangan, sehingga tanaman yang berada di segmen taman dua dan tiga sudah tertata dengan baik. Adanya pengulangan desain meningkatkan keindahan taman, sehingga pengunjung tidak bosan dengan tema yang monoton.
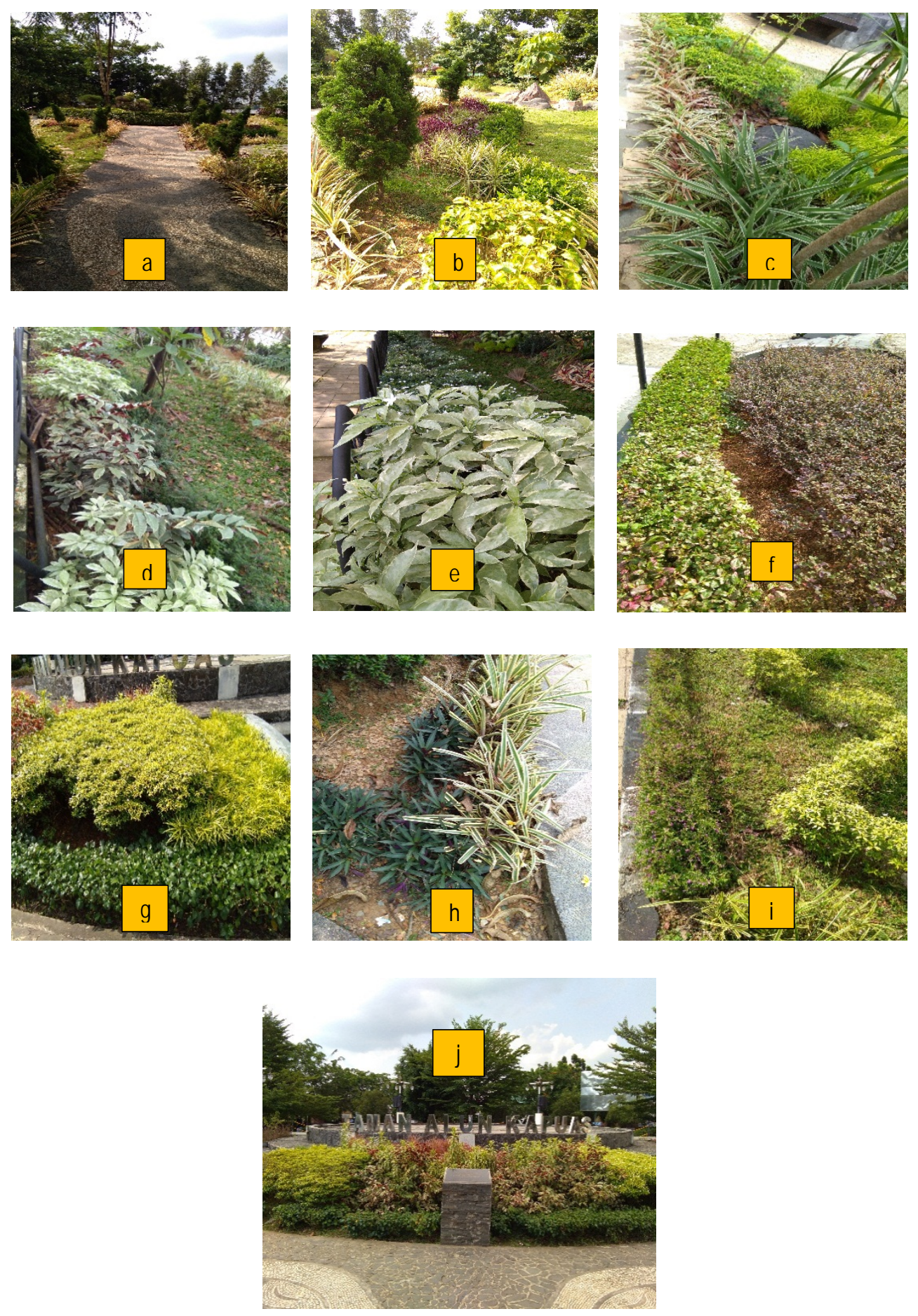

Gambar 2. Tanaman yang Mengalami Pengulangan dan Penekanan. (a - i ) Tanaman yang mengalami penulangan, (j) Tanaman yang mengalami penekanan. 
Prinsip desain berupa penekanan juga ditemukan pada segmen taman dua, dimana objek yang mengalami penekan adalah air mancur, keberhasilan dalam penekanan suatu objek, dilihat dari pengunjung yang sering datang ke segmen taman dua menuju air mancur untuk mengambil gambar dan mengabadikan sutu peristiwa. Tanaman yang mengalami pengulangan dan penekanan dapat dilihat pada Gambar 2.

Segmen taman tiga bagaian A belum memenuhi kriteria dalam prinsip desain yang brupa keeimbangan, dimana pada taman ini tanaman Papyrus (Cyperus papyrus $L$ ) yang di tanam di sisi jembatan. Tanaman papyrus di tanam diantara jembatan yang menghubungkan taman segmen tiga bagian taman $A$ dan taman B dan di tanam dua papyrus di bagian sisi taman B dan dua papyrus di bagian sisi taman A. Tanaman papyrus dapat dilihat pada Gambar 3. berikut.

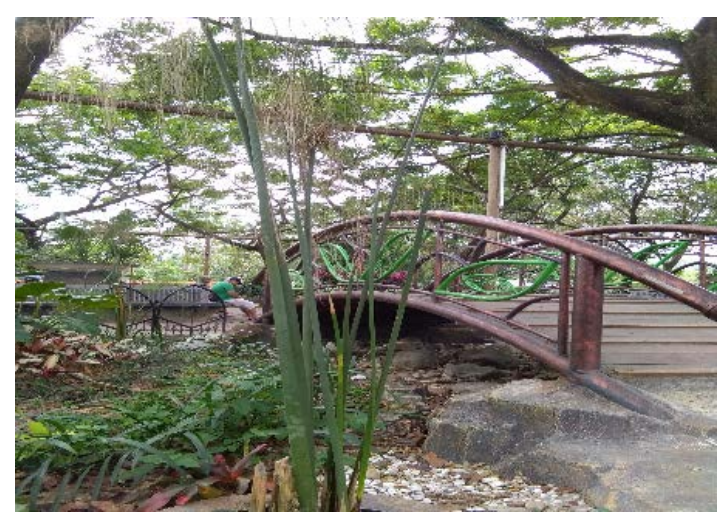

Gambar 3. Tanaman Papyrus (Cyperus papyrus $L$ ) yang mengalami tidak seimbangan

Suatu susunan yang tidak seimbang akan menimbulkan konflik atau pertentangan terutama dari sudut visual. Keseimbangan akan mewujudkan suatu kesan keselarasan (Hakim dan Utomo 2002). Keseimbangan dalam sudut visual akan memberikan kesan gerak, penempatan yang spontan dan bersifat santai.

b. Kondisi tanaman

Tanaman merupakan elemen pembentuk taman sebagai unsur utama lanskap lunak. Tanaman merupakan faktor yang dominan dalam suatu taman. Jenis-jenis tanaman yang berada di Taman Alun-Alun Kapuas saat ini dapat di lihat pada lampiran 2. Adapun kondisi tanaman tersebut dapat dilihat pada tabel 5 berikut.

Tabel 1. Kondisi Tanaman

\begin{tabular}{cccc}
\hline No & Kondisi tanaman & Nama tanaman & Persentase (\%) \\
\hline 1 & Baik & 43 & 81,13 \\
2 & Cukup baik & 5 & 9,43 \\
3 & Tidak baik & 5 & 9,43 \\
& Jumlah & 53 & 100 \\
\hline
\end{tabular}

Sumber : Data Primer, 2017

Berdasarkan Tabel 1. diketahui bahwa sebagian besar tanaman yang berada di Taman Alun-Alun Kapuas dalam kondisi baik. Tanaman yang berada pada Taman Alin-Alun Kapuas dalam kondisi baik dilihat dari dua faktor yaitu faktor syarat tumbuh tanaman dan faktor teknik budidaya (pemeliharaan tanaman). Adapun faktor-faktor yang memepengaruhi pertumbuhan tanaman menurut (Lestari dan Kencana 2008) yaitu syarat tumbuh tanaman. Tanaman akan tumbuh sehat jika kondisi lingkungan ideal dan memenuhi syarat tumbuh suatu tanaman. Syarat tumbuh ataupun syarat lingkungan ideal adalah memperhatikan ketinggian tempat, suhu, kelembapan, cahaya, kandungan air, dan kandungan unsur hara yang sesuai dengan kebutuhan tanaman. 


\section{c. Persepsi Masyarakat}

Analisis persepsi masyarakat yang dilakukan dengan wawancara dan penyebarkan kuisoner kepada pengunjung yang mengunjungi Taman Alun-Alun Kapuas dan pengunjung tersebut mengerti tentang keadaan taman. Hasil dari wawancara dan penyebaran kuisioner dapat dilihat di bawah ini.

1. Evaluasi Taman Alun-Alun Kapuas

Diagram lingkaran kuisioner persepsi masyarakat tentang kondisi Taman Alun-Alun Kapuas dapat di lihat pada Gambar 4 di bawah ini.

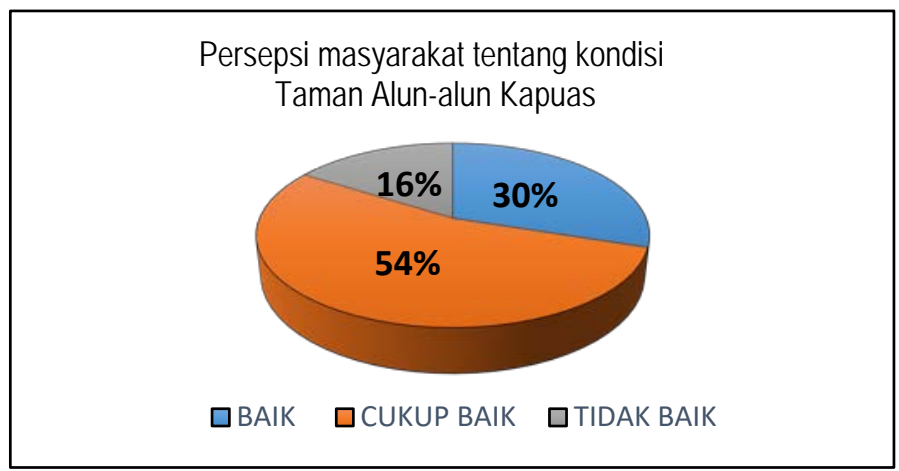

Gambar 4. Persepsi Masyarakat Tentang Kondisi Taman Alun-Alun Kapuas

Berdasarkan dari hasil Gambar 4 dapat dilihat tanggapan responden terhadap pertanyaan kuisioner mengenai persepsi masyarakat tentang kondisi Taman Alun-Alun Kapuas. Tanggapan responden terhadap item-item tersebut lebih menanggapi cukup baik dengan persentasi sebesar $54 \%$. Persepsi atau tanggapan responden lebih dominan cukup baik karena ada faktor ketidak puasan dari responden terhadap Taman AlunAlun Kapuas.

2. Evaluasi kualitas taman alun-alun kapuas

Diagram lingkaran kuisioner persepsi masyarakat tentang kualitas Taman Alun-Alun Kapuas dapat dilihat pada Gambar 5 di bawah ini.

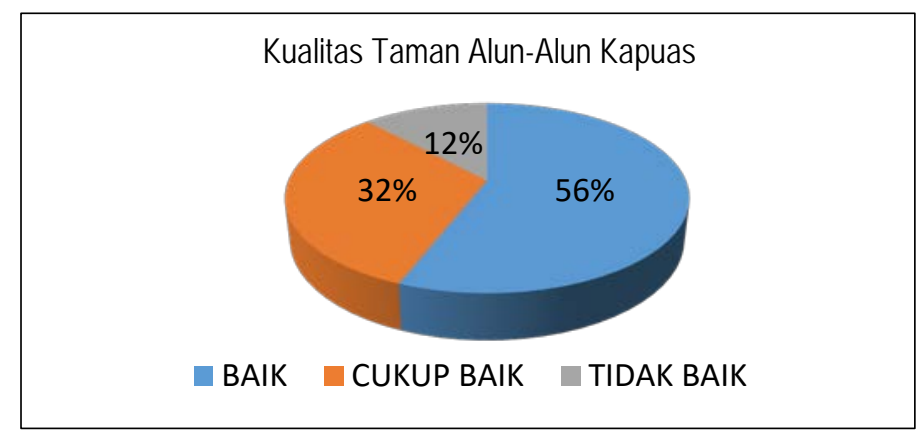

Gambar 5. Kualitas Taman Alun-Alun Kapuas

Berdasarkan dari hasil Gambar 5 dapat dilihat tanggapan responden terhadap pertanyaan kuisioner mengenai kualitas Taman Kota Alun-Alun Kapuas meliputi kebersihan lingkungan, kenyamanan, lokasi dan keadaan di Taman Alun-Alun Kapuas. Tanggapan responden terhadap item-item tersebut lebih menanggapi baik dengan persentasi sebesar $56 \%$. Persepsi atau tanggapan responden lebih dominan baik karena faktorfaktor kepuasan yang berkaitan dengan Taman Alun-Alun Kapuas dari responden terpenuhi. 


\section{d. Rekomendasi}

Rekomendasi yang diusulkan berdasarkan hasil evaluasi taman. Adapun evaluasi taman yang dapat dilakukan sebagai berikut :

1. Fasilitas Taman

Fasilitas taman perlu penambahan berupa tempat wudhu dan lampu taman. Penambahan tempat wudhu berguna untuk meminimalkan antrian ketika pengunjung mengambil air wudhu. Taman Alun-Alun Kapuas memerlukan lampu taman yang berfungsi untuk menerangi taman. Penerangan taman dapat membantu penglihatan pengunjung ketika malam hari. Pengunjung yang berada di taman pada malam hari juga tidak merasa takut dan merasa aman. Menurut (Hakim, 2004) salah satu material pendukung disebut juga elemen keras yang berupa lampu taman merupakan elemen utama sebuah taman yang fungsinya sebagai pencahayaan taman dan sebagai nilai artestik taman.

2. Kesesuaian Tema

Kesesuaian tema pada prinsip desain berupa keseimbangan perlu di perbaiki, dengan menanam ulang tanaman yang sesuai pada Taman Alun-Alun Kapuas. Menurut (Napisah, 2009) pemeliharaan dan kondisi lingkungan yang optimal bagi pertumbuhan tanaman akan memberikan nilai positip bagi peningkatan kualitas tanaman. Prinsip desain berupa pengulangan dan penekanan dalam kondisi baik sehingga perlu dipertahankan agar prinsip desain tersebut tidak rusak. Usaha tanaman tidak rusak dengan cara merawat tanaman agar terjaga bentuk dan kesehatan tanaman. Pemeliharaan tanaman berupa pengawasan terhadap kegiatan di lapangan dapat mempertahankan kondisi tanaman. Menurut (Yuslim, 2005) dengan adanya rencana kerja pelaksanaan pekerjaan di lapangan yang berupa pemeliharaan, pengaturan dan sumberdaya yang terarah jelas maka akan didapat hasil yang maksimal.

3. Aspek Kebersihan

Kebersihan pada Taman Alun-Alun Kapuas saat ini dalam kondisi cukup baik maka perlu dipertahankan dan ditingkatkan sehingga pengunjung merasa nyaman ketika berada di taman. Kebersihan dapat dipertahankan dengan memberikan himbauan-himbauan terhadap pengunjung taman agar tidak membuang sampah pada sembarangan tempat. Kebersihan juga dapat di pertahankan dengan membuat papan pengumumuan disetiap segmen taman. Penambahan tempat sampah di setiap segmen taman juga dapat mempertahankan kebersihan. Tempat sampah dapat dibuat semenarik mungkin dengan tujuan memberikan kesan kesenangan terhadap pengunjung untuk membuang sampah pada tempat yang telah disediakan. Kebersihan taman juga dapat dilakukan dengan mengadakan sebuah perlombaan yang bertemakan kebersihan. Menurut Febriana (2014) menyatakan bahwa dengan mengadakan kegiatan yang bersifat menyenangkan sekaligus edukatif seperti lomba fotografi tentang foto kebersihan yang dilakukan dengan memberikan foto kondisi lokasi sebelum dibersihkan dan setelah dibersihkan. Kegiatan lomba fotografi merupakan salah satu cara untuk menciptakan masyarakat rendah karbon. Kegiatan membersihkan kawasan dari sampah plastik dan sampah lainnya akan mengurangi produksi karbon pada kawasan tersebut.

4. Aspek Keindahan

Keindahan pada Taman Alun-Alun Kapuas saat ini dalam kondisi cukup baik. Keindahan taman dapat dipertahankan dan ditingkatkan dengan cara perawatan tanaman. Keindahan taman dapat ditingkatkan dengan cara memberikan himbauan terhadap penggunjung taman, membuat signage, dan membuat papan pengumuman. Himbauan yang berisikan tentang larangan memetik bunga, menginjak tanaman dan mencabut tanaman yang disebar setiap segmen taman yang terdapat tanaman. Keindahan taman dapat juga dilakukan tindakan pembuatan pagar untuk tanaman yang mudah patah dan rusak. Menurut Febriana, (2014) pembuatan signage yang bertuliskan peraturan dan peringatan mengenai penjelasan jika berada dikawasan yang berfungsi untuk mengingatkan pengunjung dalam bersikap selama berada didalam kawasan sehingga hal ini diharapkan dapat membantu meminimalisir sikap pengunjung yang dapat memberikan dampak buruk bagi kawasan khususnya kualitas estetika lanskap.

5. Aspek Kenyamanan

Aspek kenyamanan pada Taman Alun-Alun Kapuas saat ini dalam kondisi cukup baik. Kenyaman taman dapat dipertahankan dan ditingkatkan dengan cara perawatan tanaman dan penambahan tanaman. Kenyamanan taman dapat dipertahankan dengan perawatan tanaman yang berada pada taman. Meningkatkan kenyaman taman dengan cara penambahan pohon yang berkanopi rindang pada bagian-bagian 
segmen taman. Penambahan pohon pada segmen taman dapat dilakukan di segmen dua yaitu pada podium. Waktu siang matahari langsung terpapar kearah podium sehingga pengunjung yang berada di podium merasa tidak nyaman dengan sinar matahari. Menurut Putra (2011) penambahan pohon penaung serta semak untuk mengurangi suhu yang tinggi dari sinar matahari. Penambahan vegetasi berupa semak dan pohon juga akan meningkatkan kelembaban dan menurunkan suhu udara kawasan tersebut.

4. Kesimpulan

a. Kesesuaian tema pada Taman Alun-Alun Kapuas saat ini masih sama dengan perencanaan namun dalam desain ditemukan prinsip kesimbangan yang terganggu.

b. Tanaman pada Taman Alun-Alun Kapuas saat ini dalam kondisi baik. Persentase tanaman dalam kondisi baik sebesar 81,13\%, tanaman dalam kondisi cukup baik sebesar $5 \%$ dan tanaman dalam kondisi tidak baik sebesar $5 \%$.

c. Persepsi masyarakat terhadap Taman Alun-Alun Kapuas menanggapi cukup baik sebesar $54 \%$ terhadap faktor yang mempengaruhi evalusi taman, sedangkan masyarakat yang menanggapi baik sebesar $56 \%$ terhadap faktor-faktor yang mempengrauhi taman. Perlu peningkatan pada fasilitas taman yang dapat memberikan kenyamana pengunjung seperti kursi taman, lampu taman, tempat wudhu, dan tempat sampa.

\section{Daftar Pustaka}

Arifin, H.S., Munandar, A. Arifin, N.H.S., Pramukanto, Q., Damayanti, V.D. 2008. Buku Panduan Penataan Taman Umum, Penanaman Tanaman, penanganan Sampah dan Pemberdayaan Masyarakat. Sampoerna Hijau Kotaku Hijau, Bogor.

Febriana, P., T. 2014. Evaluasi Kenyamanan Pada Beberapa Taman Kota Di Jakarta Pusat. Bogo: Institute Pertanian Bogor.

Grey, G.W. dan Deneke, F.I. 1986. Urban Forestry. New York : Johon Wileyand Sons.

Hakim, R. 2004. Arsitektur Lansekap, Manusia, Alam dan Lingkungan. Jakarta: FALTL Universitas Trisakti.

Hakim, R. dan Utomo, H. 2002. Komponen Perancangan Arsitektur Lansekap Prinsip-Prinsip dan Aplikasi Disain. Jakarta : Bumi Aksara.

Lestari, G., S. P. dan Kencana, I. P., S. P. 2008. Galeri Tanaman Hias Lansekap. Penebar Swadaya. Jakarta.

Nagtegaal L, Nas PJM. 2000. Jakarta Greenery An Essay on Urban Natural Environmen. Peter J.M. Nas Personal website:pp. 263-290. [terhubung berkala] Published in: Jakarta-Batavia, Socio-cultural essay. KITLV Press, Leiden, 2000. [terhubung berkala].

Napisah, I. 2009. Evaluasi Aspek Fungsi dan Kualitas Estetika Tanaman Lanskap Kebun Raya Bogor (Kasus: Pohon dan Pedu) [Skripsi]. Departemen Arsitektur Lanskap. Fakultas Pertanian. Institute Pertanian Bogor.

Putra, P., T. 2011. Evaluasi Kenyamanan Pada Beberapa Taman Kota di Jakarta Pusat. Bogo: Institute Pertanian Bogor.

Yuslim, S 2005. Kajian Efektifitas Pengelolaan Pemeliharaan Ruang Terbuka Hijau Di Kawasan Pemukiman Lipo Karawaci. Jurnal Arsitektur Lanskap Perencanaan, Perabncangan Dan Pengelolaan Bentang Alam Universitas Trisakti. UPT Penerbit Dan Percetakan Universitas Trisakti. Jakarta 